International Journal on Cloud Computing: Services and Architecture (IJCCSA)

ISSN: 2231 - 5853 [Online]; 2231 - 6663 [Print]
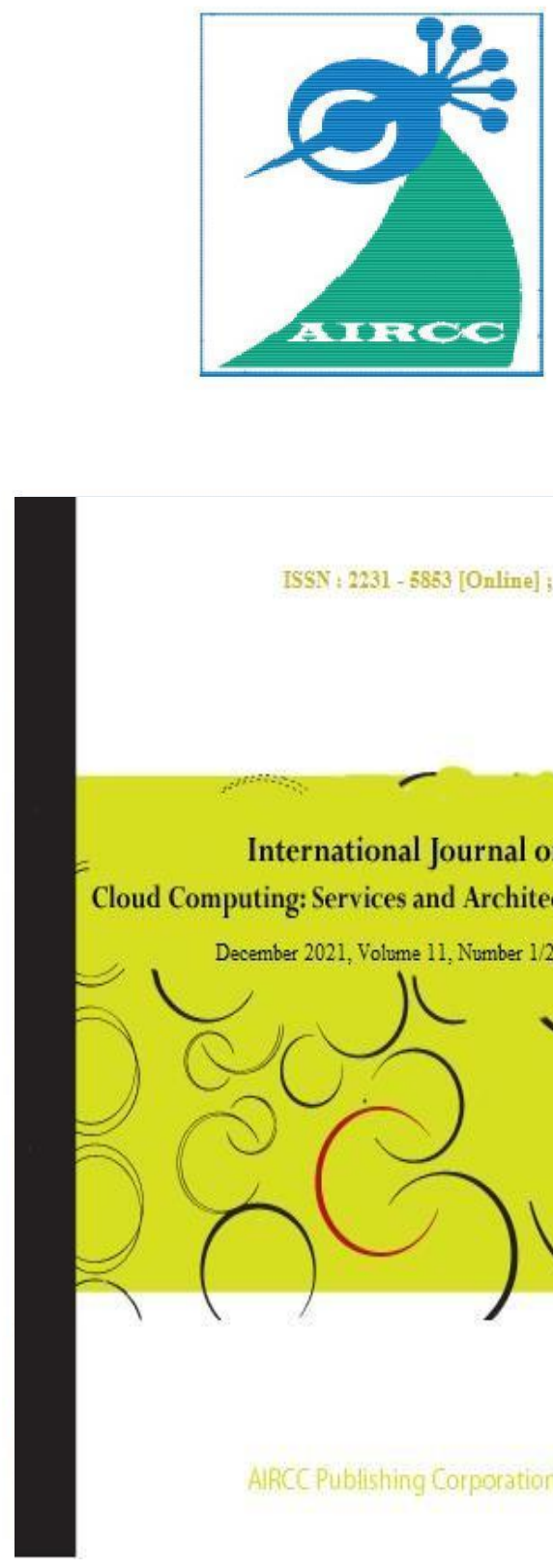

ISSN : 2231 - 5853 [Online] ; 2231 - 6663

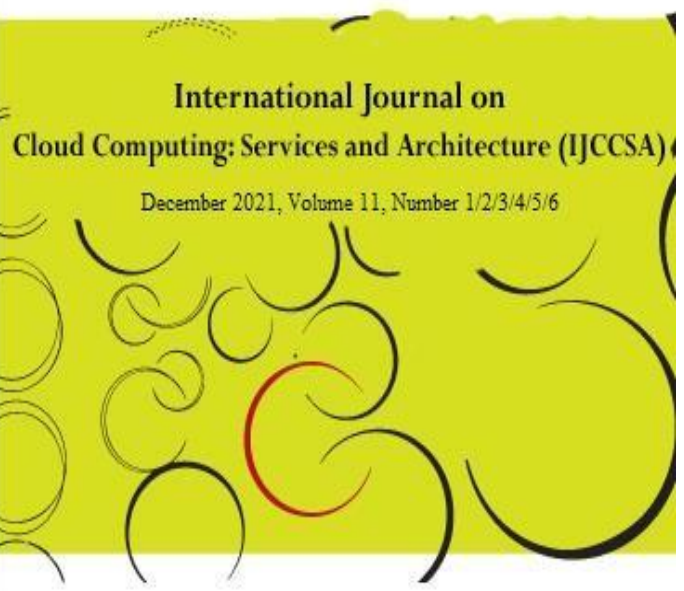

AlRCC Publishing Corporation

https://airccse.org/iournal/iiccsa/index.html 
Cloud computing helps enterprises transform business and technology. Companies have begun to look for solutions that would help reduce their infrastructures costs and improve profitability. Cloud computing is becoming a foundation for benefits well beyond IT cost savings. Yet, many business leaders are concerned about cloud security, privacy, availability, and data protection. To discuss and address these issues, we invite researches who focus on cloud computing to shed more light on this emerging field. This peer-reviewed open access Journal aims to bring together researchers and practitioners in all security aspects of cloudcentric and outsourced computing, including (but not limited to):

\section{Topics of interest include but are not limited to:}

- Cloud Application, Infrastructure and platforms

- Design Tool for Cloud Computing

- Cloud Business

- Service-Oriented Architecture in Cloud Computing

- Cloud based, Parallel Processing

- Virtualization on Platforms in the Cloud

- Location Based Services, Presence, Availability, and Locality

- Mobile Clouds for new millennium, mobile devices

- Social Clouds (Social Networks in the Cloud)

- Maintenance and Management of Cloud Computing

- Cloud Computing Architecture

- Cloud Applications in Vertical Industries

- Cloud storage and file systems

- Networks within cloud systems, the storage area, and to the outside

- Virtualization in the context of cloud computing platforms

- System integration, virtual compute clusters

- Consolidation

- NoSQL data stores

- Performance, SLA management and enforcement

- Resource provisioning

- Security techniques for the Cloud

- Energy management and programming environments

- Data storage and management in Cloud computing

- Case Studies and Theories in Cloud Computing

- The Open Cloud: Cloud Computing and open source

- Edge and Internet-of-Things (IoT)

- Big Data and blockchain applications

- $\mathrm{AI} / \mathrm{ML}$ in Cloud Computing 


\title{
Members of the Editorial Board
}

\section{Editor In Chief:}

\author{
Chin-Chih Chang, Chung Hua University, Taiwan
}

\section{Associate Editors}

Yew Kee Wong, HuangHuai University, China

\section{Editorial Board}

Ashutosh Kumar Dubey, Trinity Institute of Technology \& Research Bhopal, India Chandradeep Kasturi, Indian institute of technology Kharagpur, India

Chang-Wu Yu, Chung Hua University, Taiwan

Demian Antony D'Mello, St. Joseph Engineering College Mangalore, India

Hung-Chi Su, Arkansas State University, USA

Isa Maleki, Islamic Azad University, Iran

Jeyanthi N, Vellore Institute of Technology, India

Jitendra Chauhan, iViZ Technosolutions Pvt Ltd, India

Jong P. Yoon, Mercy College-New York, USA

Alagarsamy K, Madurai kamaraj university, India

Husam Suleiman, University of Waterloo, Canada

Kalpesh Wandra, Gujarat Technological University, India

Kamaljit I. Lakhtaria, Atmiya Institute of Technology \& Science-Rajkot, India

Kashif Munir, University of Hafr Al Batin, Saudi Arabia

Legand L. Burge, Howard University, USA

Roberts Masillamani M, Hindustan University, India.

Maniza Hijab, Muffakham Jah College of Engineering and Technology, India

Manjaiah D.H, Mangalore University, India

Mohammed M. Kadhum, Universiti Utara Malaysia, Malaysia

Mukesh Kumar, Maharshi Dayanand University, India

Mukesh Negi, TechMahindra, India

Muzahid Hussain, Thapar University, India

Mydhili K Nair, M S Ramaiah Institute of Technology, India

Naser Movahedinia, University of Isfahan, Iran

Natarajan Meghanathan, Jackson State University, USA 
Nobuyuki Nezu, Arkansas Tech University, USA

Paulo R M. Maciel, Federal University of Pernambuco, Brazil

Poonam sinha, Barkatullah University, India

Pushpendra Kumar Pateriya, Lovely Professional University, India

Ravendra Singh, Mahatma Jyotiba Phule Rohilkhand University, India

Riri Fitri Sari, University of Indonesia, Indonesia

Salah M. Saleh Al-Majeed, University of Essex, United Kingdom

Satria Mandala, Maliki Islamic State University, Indonesia

Sebastian Floerecke, University of Passau, Germany

Selwyn Piramuthu, University of Florida, USA

Shefalika Ghosh Samaddar, Motilal Nehru National Institute of Technology Allahabad, India

Sherin Zafar, Faculty of Engineering jamia Milia Islamia, India

Shiyong Lu, Wayne State University, USA

Somayaji Siva Rama Krishnan, Vellore Institute of Technology University, India

Somayeh abdi, Islamic Azad University, Iran

Somayeh Mohammadi, Islamic Azad University, Iran

Subrata Dutta, Jadavpur University, India

Sudarshan Patel, Gujarat Technological University, India

Tran Cong Hung, PTIT (Posts and Telecoms Institute of Technology), Viet Nam

Vasista T.G, King Saud University, Saudi Arabia

Tin Tin Yee, University of Computer Studies-Yangon, Myanmar

Yahya Slimani, Faculty of Sciences of Tunis, Tunisia

Yao-Nan Lien, National Chengchi Univerity, Taiwan

Yaser Miaji, College of Telecommunication and Electronic, Saudi Arabia

Yatindra Nath Singh, Indian institute of technology-Kanpur, India

Yufeng Wang, Nanjing Univerity of Posts and Telecommunications, China

Zailani Mohamed Sidek, University of Technology Malaysia, Malaysia

https://airccse.org/journal/ijccsa/index.html 


\section{Paper Submission \& Manuscript preparation Guide}

\section{Paper Submission}

Authors are invited to submit papers for this journal through Email: ijccsajournal@airccse.org or ijccsa@aircconline.com or through Submission System. Submissions must be original and should not have been published previously or be under consideration for publication while being evaluated for this Journal. For paper format download the template in this page

\section{Manuscript Template}

\section{Review Process}

Submissions are accepted for review with the understanding that the same work has been neither submitted to, nor published in, another publication. Simultaneous submission to other publications will result in immediate rejection of the paper. Papers are not within the journal scope will be rejected immediately after the pre review process.

All manuscripts will be subject to a well established, fair, unbiased peer review and refereeing procedure, and are considered on the basis of their significance, novelty and usefulness to the Journals readership. The reviewing structure will always ensure the anonymity of the referees $\&$ it will be reviewed by 3 experts in the field. The review output will be one of the following decisions:

\section{Accept}

2. Accept with minor changes

3. weak Accept with major changes

4. Reject

The review process may take approximately two $\sim$ three months to be completed. The Editor reserves the right to reject a paper if it does not meet the aims and scope of the journal, it is not revised well.

\section{Copy Right Form}

After submitting final manuscript, you can get copy right form from Journal secretary

\section{Contact Us}

\section{Here's where you can reach us :}

ijccsajournal@yahoo.com or ijccsajournal@airccse.org or ijccsa@aircconline.com 


\section{Indexing}

\section{Abstracting \& Indexing Services:}

The articles of IJCCSA are indexed/abstracted in the following indexing services.
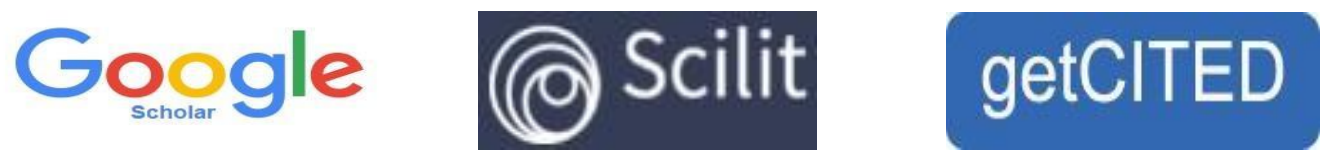

docstac
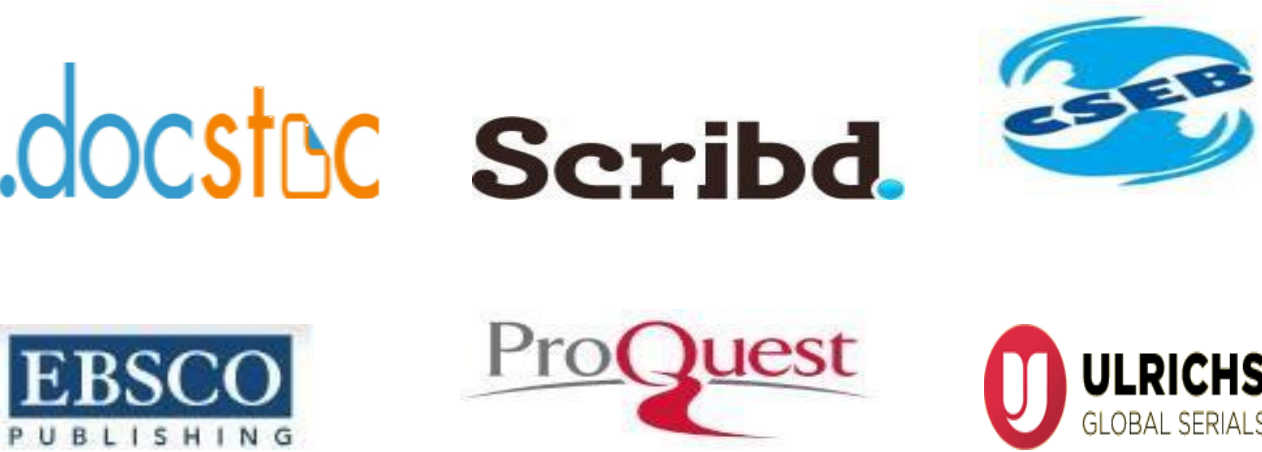

\section{Cn<i中国知细 www.cnki.net} 中国知识基础设施工程

Bibliographic Information
ISSN : 2231 - 6663
e-ISSN : 2231 - 5853
doi $\quad:$ 10.5121/ijecsa 


\title{
Google Scholar Indexing
}

\author{
H -Index - 20, Citations 1316, i10-Index 35 \\ more details \\ https://scholar.google.com/citations?hl=en\&user=aqL6awEAAAAJ
}

\begin{tabular}{lrr} 
Cited by & \multicolumn{2}{c}{ VIEW ALL } \\
& All & Since 2017 \\
\hline Citations & 1316 & 759 \\
h-index & 20 & 15 \\
i10-index & 35 & 26
\end{tabular}

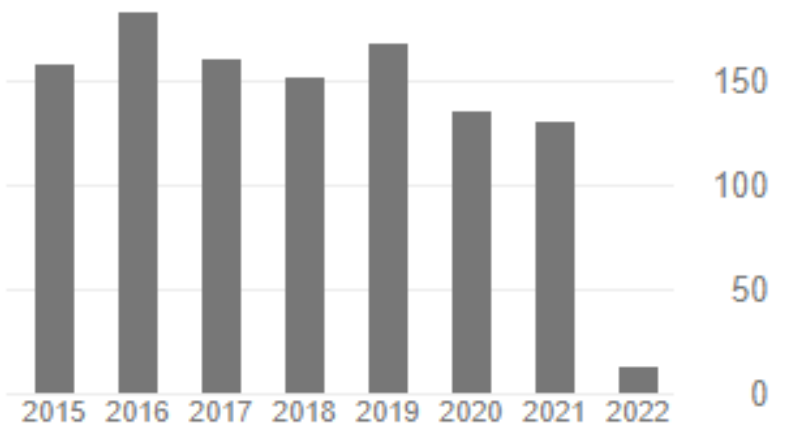

